\title{
Characterization and possible functions of a new filamentous bacteriophage from Vibrio cholerae 0139
}

\author{
Elena A. Jouravleva, ${ }^{1}$ Gregory A. McDonald, ${ }^{1}$ Claude F. Garon, ${ }^{2}$ \\ Mary Boesman-Finkelstein ${ }^{1}$ and Richard A. Finkelstein ${ }^{1}$
}

Author for correspondence: Richard A. Finkelstein. Tel: +1573 882 4117. Fax: + 15738847885. e-mail: rfinkels@mail.coin.missouri.edu

1 Department of Molecular Microbiology and Immunology, School of Medicine, University of Missouri, Columbia, MO 65212, USA

2 Rocky Mountain Laboratories, Hamilton, MT 59840, USA
The emergence and rapid rise to dominance of Vibrio cholerae 0139 in India and Bangladesh in 1992 led to the consideration that choleraphage might serve as both a selective mechanism and a means for horizontal transmission of genetic information. A filamentous phage '493' from 0139 strain AJ27-493 has been purified and partially characterized. The phage was inactive on classical biotype $V$. cholerae 01 but it was active on El Tor biotype strains isolated prior to 1994 when EI Tor re-emerged in Bangladesh. More recent EI Tor isolates were all resistant to the phage. The phage was also active on 0139 strains. Unlike the filamentous ctx $\phi$, the receptor for 493 is not TcpA. The phage genome was a $9.3 \mathrm{~kb}$ closed circular single-stranded molecule containing a $0.4 \mathrm{~kb}$ double-stranded stem supporting a $2 \mathrm{~kb}$ single-stranded loop. A 283 bp fragment was cloned and used as a probe in Southern hybridization, in parallel with total phage 493 DNA. These probes hybridized both chromosomally and extrachromosomally with most 0139 strains, but not with 01 strains. Infection of hybridization-negative El Tor or 0139 strains resulted in the presence of hybridizing loci (both plasmid and chromosomal), in the appearance of an $18 \mathrm{kDa}$ protein, and in marked alterations in colonial morphology. Phage 493 is clearly distinct from other 0139 choleraphages which have been described. Phage 493 DNA hybridized with an encapsulated non-01 (031) strain (NRT365) which was isolated before 0139 was recognized. NRT36S also produces a phage which can infect El Tor strains with low efficiency. Further studies may reveal whether bacteriophage play a role in the emergence and the territoriality of new choleragenic vibrios.

Keywords: Vibrio cholerae O139, filamentous bacteriophage, choleraphage host range, cholera vibrio territoriality, horizontal gene transfer

\section{INTRODUCTION}

Until 1992, out of approximately 140 Vibrio cholerae serogroups only strains of serogroup $\mathrm{O} 1$ were known to cause epidemic cholera, while non-O1 strains were occasionally associated with sporadic cases of diarrhoea. In 1992, a new non-O1 V. cholerae serogroup, O139 (syn. Bengal), emerged in India and Bangladesh, displacing the resident $\mathrm{O} 1 \mathrm{El}$ Tor biotype and causing a major epidemic of cholera which showed signs of spreading (Albert, 1994). However, the O1 El Tor

Abbreviation: EM, electron microscopy. biovar re-emerged and is again dominant in India and Bangladesh (Sharma et al., 1997). The O139 serogroup is closely related to the O1 El Tor biovar (Kaper et al., 1995) but there are important differences. V. cholerae O139 lacks the O1-specific antigen and expresses a polysaccharide capsule as a result of replacement of the O1 antigen $r f b$ locus DNA by exogenous DNA encoding O139 antigen and capsular polysaccharide synthesis (Bik et al., 1995; Stroeher et al., 1995). The mechanism responsible for this DNA substitution has not yet been identified. O139 also expresses the mannose-sensitive haemagglutinin which is characteristic of the El Tor biotype (Albert, 1994). The emergence, rapid rise to dominance and subsequent decline of $V$. cholerae $\mathrm{O} 139$ 
led us to consider choleraphage as both a selective mechanism and a means for horizontal transmission of genetic information. Temperate and filamentous bacteriophages (Kar et al., 1996; Pajni et al., 1995a ; Reidl \& Mekalanos, 1995) have previously been identified in $V$. cholerae O139. Temperate choleraphages can integrate randomly into the $V$. cholerae chromosome, mediate generalized transduction (Rowe \& Frost, 1992), participate in horizontal gene transfer and alter various host characteristics (Mitra, 1989; Siddiqui \& Bhattacharyya, 1987). With regard to these properties, we highlight older observations (Gay, 1935) in which Pasricha, de Monte and Gupta found in 1931 that 20\% of a series of 355 non-agglutinatable (i.e. non-O1) water vibrios were lysable by cholera bacteriophage. In some instances, the secondary cultures, which appeared after lysis, were agglutinatable with cholera antiserum, possessed a highly potent agglutinogen for true cholera organisms (which the parent culture did not have) and completely absorbed the agglutinins from an antiserum to true cholera ... 'The effect of phage has been, then, to add an agglutinogen to the antigenic structure of the strain, and to bring the strain into what appears to be a close serological relationship with V. cholerae.'

In this report, we characterize a new filamentous choleraphage, from V. cholerae O139 strain AJ27-493 (' 493 '), which can infect different serovars and biotypes and integrate into the chromosome. Its ability to inhibit all but the most recent El Tor strains suggests that it could play a role in vibrio territoriality, and its ability to integrate chromosomally and exist extrachromosomally provides a potential mechanism for horizontal transmission of genetic information.

\section{METHODS}

Bacterial strains. Thirty-three $V$. cholerae $0139,46 \mathrm{~V}$. cholerae $\mathrm{O} 1$ biotype $\mathrm{El}$ Tor, $10 \mathrm{~V}$. cholerae $\mathrm{O} 1$ classical, one atypical O1 strain, MO1 (Pajni et al., 1995b), and non-O1 O31 strain NRT36S (Table 1), Vibrio parahaemolyticus, Vibrio bollisae, Vibrio vulnificus, Vibrio fluvialis, Vibrio harveyi and Aeromonas ('Vibrio') damsela were used in this study. Of these, a series of carefully collected and preserved fresh O139 and $\mathrm{O} 1 \mathrm{El}$ Tor $V$. cholerae isolates from Bangladesh, obtained from 1993 to 1996 from J. Albert (International Centre for Diarrhoeal Disease Research, Dhaka, Bangladesh), were lyophilized from the confluent growth streaked from the primary colony from patients' stools on TCBS agar (Oxoid). Unlike other stock cultures (Finkelstein et al., 1997), these were colonially homogeneous. Other cultures were from ATCC, J. Johnson (VA Medical Center, Baltimore, MD, USA), J. Mekalanos (Harvard Medical School, Boston, MA, USA), G. B. Nair (National Institute of Cholera and Enteric Diseases, Calcutta, India), Y. Takeda (International Medical Center of Japan, Tokyo, Japan), R. Taylor (Dartmouth Medical School, Hanover, NH, USA), K. Wachsmuth (Centers for Disease Control and Prevention, Atlanta, GA, USA) and our laboratory collection (University of Missouri, MO, USA). Colony morphology and opacity were evaluated as previously described (Finkelstein et al., 1997). To evaluate the potential role of TcpA as a receptor (Waldor \& Mekalanos, 1996) for phage 493, ToxR- mutants of AJ27-493 were made according to a modification of a previously described technique (Waldor
\& Mekalanos, 1994). For this purpose, we used the EcoRI $630 \mathrm{bp}$ internal fragment of toxR labelled with digoxigenin as a probe for confirmation of the correct integration of pVM55 (Miller \& Mekalanos, 1988). R. Taylor also generously provided strain KHT52, a $\Delta t c p A$ mutant (Thelin \& Taylor, 1996).

Choleraphage techniques. For isolation of phage, $V$. cholerae O139 strain AJ27-493 was grown in $500 \mathrm{ml} \mathrm{LB}$ in 21 Erlenmeyer flasks for $48 \mathrm{~h}$ at $37^{\circ} \mathrm{C}$ with shaking (100 r.p.m.). Free phage particles were collected after removing cells by centrifugation at $10000 \mathrm{~g}$ for $20 \mathrm{~min}$ and $20000 \mathrm{~g}$ for $20 \mathrm{~min}$, and then filtration of the supernatant through $0 \cdot 2 \mu \mathrm{m}$ nitrocellulose filters. For preparation of nucleic acids and electron microscopy (EM), phage was pelleted from the filtrate by ultracentrifugation at $300000 \mathrm{~g}$ for $3 \mathrm{~h}$ and resuspended in buffer $\left(10 \mathrm{mM}\right.$ Tris $/ \mathrm{HCl}, 10 \mathrm{mM} \mathrm{CaCl}, 10 \mathrm{mM} \mathrm{MgCl}_{2}$, $10 \mathrm{mM} \mathrm{NaCl}, \mathrm{pH} 7 \cdot 4$ ). For heat inactivation, aliquots of filtrate were placed in a water bath at various temperatures for 5 and $10 \mathrm{~min} ; \mathrm{pH}$ resistance was tested by changing the $\mathrm{pH}$ in aliquots of the filtrate for 5 min then adjusting it back to $\mathrm{pH} 7$. Chloroform sensitivity was also evaluated. Phage survival rates and sensitivity of strains to phage were determined by plaque counting. Aliquots $(0.01 \mathrm{ml})$ of serial dilutions of phage-containing samples were plated on soft LB agar $(0.4 \%)$ overlays seeded with indicator strains. The overlays were prepared by inoculating $5 \mathrm{ml} 0.4 \%$ LB agar with $10 \mu \mathrm{l}$ of $\sim 10^{8}$ cells per $\mathrm{ml}$ culture of the indicator strain grown for $\sim 3 \mathrm{~h}$ in $\mathrm{LB}$ broth at $37^{\circ} \mathrm{C}$ with shaking.

DNA analytical methods. Total DNA was prepared by alkaline lysis with vortexing using an RPM kit (Bio101). Virion DNA was extracted according to Sambrook et al. (1989). Plasmid DNA was prepared using the Wizard Plus SV Miniprep system (Promega). Enzyme digestions were performed as recommended by the manufacturers (BioLab and Boehringer Mannheim). DNA fragments were separated by agarose gel electrophoresis in TAE buffer (Sambrook et al., 1989). Labelling of DNA probes and Southern hybridization were done using the Genius system (Boehringer Mannheim). For cloning of the phage DNA fragments, pCR-Script Amp SK(+) Cloning kit (Stratagene) was used.

EM. Bacteriophage-containing samples were diluted in $2 \%$ ammonium molybdate $(\mathrm{pH} 6.5)$, incubated for $15 \mathrm{~min}$ at room temperature and mounted on freshly prepared Parlodioncoated grids as previously described by Garon (1982). A formamide modification of the Kleinschmidt technique (Garon, 1986) was used for DNA microscopy. Grids were examined in a Philips CM-10 transmission electron microscope.

SDSPAGE. Preparations of total cell protein were analysed on $10 \%$ SDS polyacrylamide gels as previously described by Laemmli (1970) and visualized by the silver staining method (Bio-Rad).

\section{RESULTS}

\section{Choleraphage 493}

After preliminary examination of several $V$. cholerae O139 strains, strain AJ27-493, a carefully preserved single colony isolate from Bangladesh in 1994, was chosen for further study. It was grown for $48 \mathrm{~h}$ and the culture supernatants were collected for identification of the phage ('493'). To confirm that the preparations did not contain any viable bacterial cells, the supernatants 
Table 1. Host range of phage 493 for $V$. cholerae

\begin{tabular}{|c|c|c|c|c|c|c|c|c|c|}
\hline Serovar* & Source & Year & Strain & Sensitivity $\dagger$ & Serovar* & Source & Year & Strain & Sensitivity $\dagger$ \\
\hline \multirow[t]{34}{*}{ O139 } & \multirow[t]{2}{*}{ Andhra Pradesh, India } & \multirow{2}{*}{1993} & \multirow{2}{*}{$\begin{array}{l}\text { AP1-1 } \\
\text { AP2-1 }\end{array}$} & ++++ & & Philippines & \multicolumn{2}{|r|}{ R4459 } & +++ \\
\hline & & & & $+++t$ & & Ethiopia & 1970 & VRL1848 & +++ \\
\hline & Calcutta, India & \multicolumn{2}{|r|}{ SG25-1 } & - & & Bangladesh & 1964 & B1716 & +++ \\
\hline & Madras, India & \multicolumn{2}{|r|}{ MO45 } & ++++ & & & & $\begin{array}{l}\text { B1716 } \\
\text { B1997 }\end{array}$ & +++ \\
\hline & Madurai, India & & MDO12 & ++++ & & & 1975 & V15503 & +++ \\
\hline & Maharashtra, India & & PO2 & ++++ & & & & N16961 & +++ \\
\hline & & & PO7 & ++++ & & Texas, USA & 1981 & $1064-81$ & +++ \\
\hline & Vellore, India & & VO20-1 & ++++ & & Peru & 1991 & 6707 & +++ \\
\hline & Bangladesh & & $1837(\mathrm{O}) \ddagger$ & $+++t$ & & & & 6709 & +++ \\
\hline & & & $1838(\mathrm{O})$ & +++ & EO & Celebes & 1937 & MAK757 & +++ \\
\hline & & & $(\mathrm{T})$ & $+++t$ & & Philippines & 1961 & $26-3$ & +++ \\
\hline & & & $1852(\mathrm{O})$ & ++++ & & Burma & 1963 & \multirow{2}{*}{$27 / 63$} & +++ \\
\hline & & & $1855(\mathrm{~T})$ & ++++ & & Vietnam & 1964 & & +++ \\
\hline & & & $4450(\mathrm{O})$ & +++ & & & & $\begin{array}{l}3083 \\
3148-11\end{array}$ & ++ \\
\hline & & & $4460(\mathrm{O})$ & ++++ & & Tehran, Iran & 1965 & $\mathrm{I} 86-\mathrm{T}$ & +++ \\
\hline & & 1994 & $\mathrm{AJ} 27-370(\mathrm{O})$ & ++++ & & Ghana & 1970 & VRL1824 (O) & +++ \\
\hline & & & $\mathrm{AJ} 27-404(\mathrm{O})$ & ++++ & & & & $(\mathrm{T})$ & +++ \\
\hline & & & AJ27-425 (O) & +++ & & Bangladesh & 1969 & G27702 & +++ \\
\hline & & & AJ27-439(O) & ++++ & & & 1980 & $\mathrm{U} 22631(\mathrm{~T})$ & +++ \\
\hline & & & AJ27-493(O) & +++ & & & & $\mathrm{U} 22631(\mathrm{O})$ & +++ \\
\hline & & & $\mathrm{AJ} 27-495(\mathrm{O})$ & +++ & & & 1993 & AI-13104 & +++ \\
\hline & & & AJ27-513 (O) & ++++ & & & & AI-16184 & +++ \\
\hline & & & AJ27-514 (O) & ++++ & & & & AI-17231 & +++ \\
\hline & & 1995 & 1658 & ++++ & & & & AI-18570 & +++ \\
\hline & & & 1433569 & ++++ & & & & AI-19571 & +++ \\
\hline & & & 1433574 & $+++t$ & & & 1994 & AJ-17564 & - \\
\hline & & & 150549 & ++++ & & & & AJ-19290 & +++ \\
\hline & & & 150648 & ++++ & & & & AJ-22606 & +++ \\
\hline & & 1996 & 1936 & $+++t$ & & & & AJ-24040 & +++ \\
\hline & & & 19641 & ++++ & & & & AJ-3422 & +++ \\
\hline & & & 19936 & ++++ & & & 1995 & 1718 & + \\
\hline & & & 20479 & ++++ & & & & 20492 & + \\
\hline & & & 20583 & ++++ & & & & $150640(\mathrm{O})$ & - \\
\hline & & & 21732 & ++++ & & & & $(\mathrm{T})$ & - \\
\hline Atypical-O1 & India & 1993 & MO1 & ++++ & & & & 150659 & - \\
\hline $\mathrm{O} 31$ & Japan & 1990 & NRT36S & - & & & & 150668 & - \\
\hline $\mathrm{O} 1, \mathrm{CI}$ & Sudan & 1942 & Sm\#6 & - & & & & 150678 & - \\
\hline & Calcutta, India & 1945 & $569 \mathrm{~B}$ & - & & & & 1434450 & - \\
\hline & Bangladesh & 1970 & $\mathrm{H} 23448$ & $(+)$ & & & & 1433875 & - \\
\hline & & 1986 & 19073 & - & & & & 1433930 & - \\
\hline & & & 20221 & $(+)$ & & & & 1434625 & - \\
\hline & & & 21552 & - & & & 1996 & 2073 & - \\
\hline $\mathrm{CO}$ & Afghanistan & 1963 & 165 & - & & & & 19235 & - \\
\hline & Calcutta, India & 1953 & CA472 & - & & & & 19992 & - \\
\hline & & 1964 & O395 & - & & & & 20049 & - \\
\hline & Bangladesh & 1985 & VC6832 & + & & & & 20259 & - \\
\hline EI & Thailand & 1966 & HP30 & ++ & & & & 20270 & - \\
\hline & & & HP5-1 & ++ & & & & & \\
\hline
\end{tabular}

*C, Classical; E, El Tor; I, Inaba serotype; O, Ogawa serotype.

+- , No plaques were formed; + , plaques were formed and expressed as,,++++++ and ++++ in order of increasing amounts of lysis: $(+)$, suppression of growth only with undiluted phage preparation.

$\ddagger(\mathrm{O})$ or $(\mathrm{T})$, relatively opaque or translucent colony types, respectively (Finkelstein et al., 1997). 

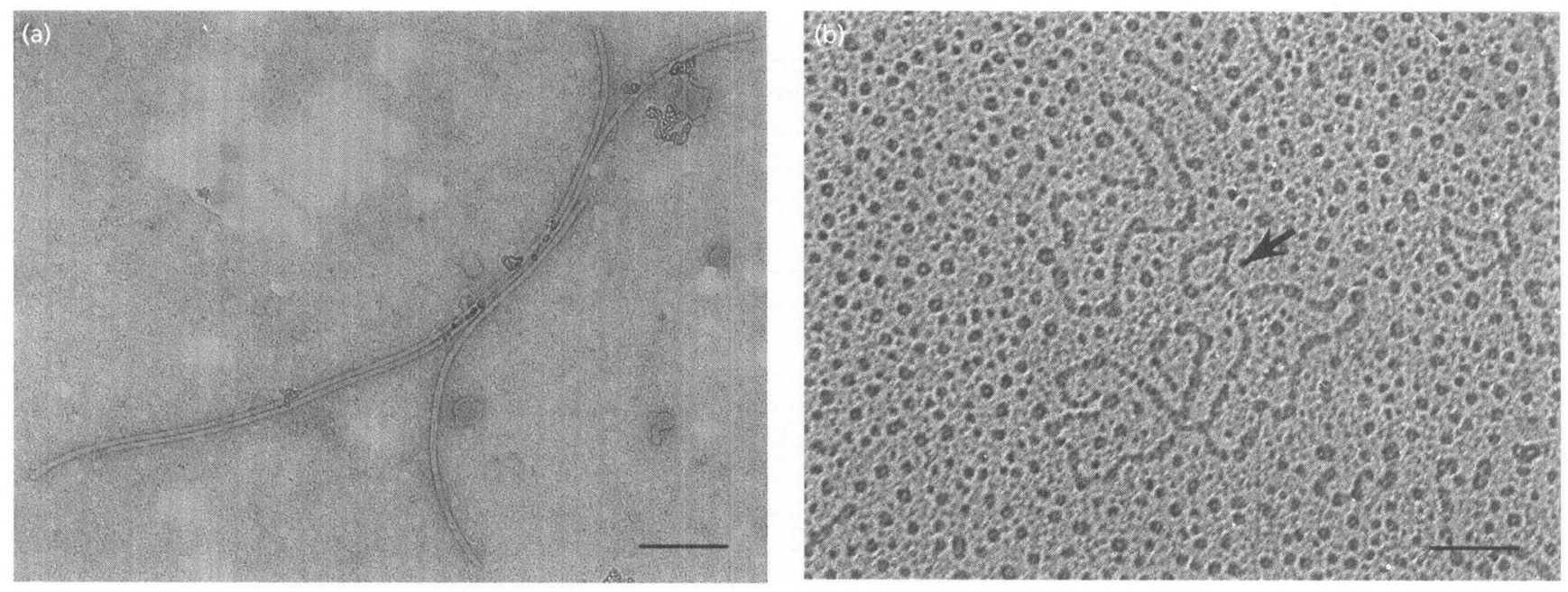

Fig. 1. EM of phage 493. (a) Negative-stained virions of choleraphage 493 . Bar, $26 \mathrm{~nm}$. (b) Genome of phage 493 showing $9.3 \mathrm{~kb}$ single-stranded closed circular DNA with a $0.4 \mathrm{~kb}$ double-stranded stem supporting a $2 \mathrm{~kb}$ single-stranded loop (arrow) perhaps representing a transposable element. Bar, $167 \mathrm{~nm}$.
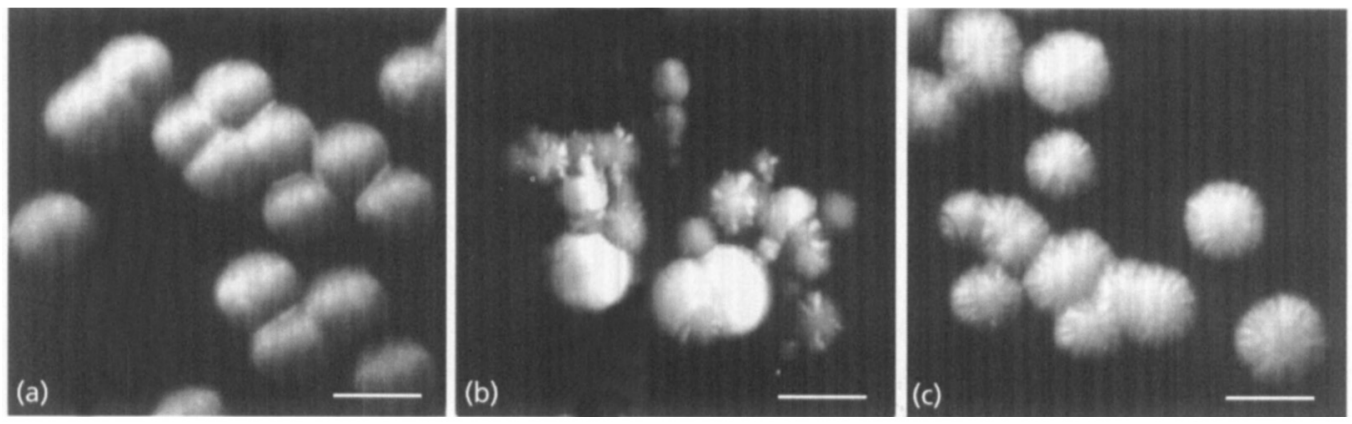

Fig. 2. Colony morphology of 0139 strain AJ27-404. (a) Wild-type; (b) cells after infection with phage 493; and (c) cells after infection with phage PO7. Bar, $2 \mathrm{~mm}$.

were streaked on LB agar plates which were incubated overnight at $37^{\circ} \mathrm{C}$. EM of phage 493 revealed the filamentous nature of the particle with an estimated width of $2.6 \mathrm{~nm}$ and variable length (Fig. 1a). In some preparations, one end of the phage appeared to carry slender fibres. The phage was resistant to $\mathrm{pH}$ values of $2 \cdot 8-11 \cdot 8$ and to heat treatment up to $60^{\circ} \mathrm{C}$ for $10 \mathrm{~min}$, but it was totally inactivated at $75^{\circ} \mathrm{C}$ and by chloroform treatment. Plaque-forming ability was sensitive to proteolytic enzymes (chymotrypsin, Pronase A, proteinase $\mathrm{K}$ and trypsin) and resistant to lysozyme. The phage genome was resistant to RNase but was completely digested by DNase 1. EM analysis (Fig. 1b) indicated that the genome of bacteriophage 493 was an approximately $9.3 \mathrm{~kb}$ single-stranded closed circle DNA molecule containing a $0.4 \mathrm{~kb}$ double-stranded stem supporting a $2 \mathrm{~kb}$ single-stranded loop.

After partial digestion of virion DNA with HaeIII, a $283 \mathrm{bp}$ fragment, putatively from the stem region, was cloned into the Srfl site of the pCR-Script SK(+) Amp vector to generate pEAJ46, which was later used as a probe. The $283 \mathrm{bp}$ fragment had no DNA homology to known sequences in GenBank. The double-stranded replicative forms of phage DNA isolated from the host strain were digested with several endonucleases. EcoRI treatment revealed only a single fragment; the HindIII digest yielded two fragments of approximately 2.3 and $7 \mathrm{~kb}$; no sites were found for Xhol, PstI, EcoRV or BamHI.

\section{Host range of choleraphage 493}

In soft agar overlay assays with indicator strains (Table 1), supernatants of strain 493 containing $10^{11}$ p.f.u. $\mathrm{ml}^{-1}$ produced turbid plaques on 32 out of 33 strains of O139, on 31 out of 46 strains of O1 biotype El Tor and on atypical-O1 strain MO1, but not on the encapsulated O31 strain NRT36S. With classical biotype O1 strains, 


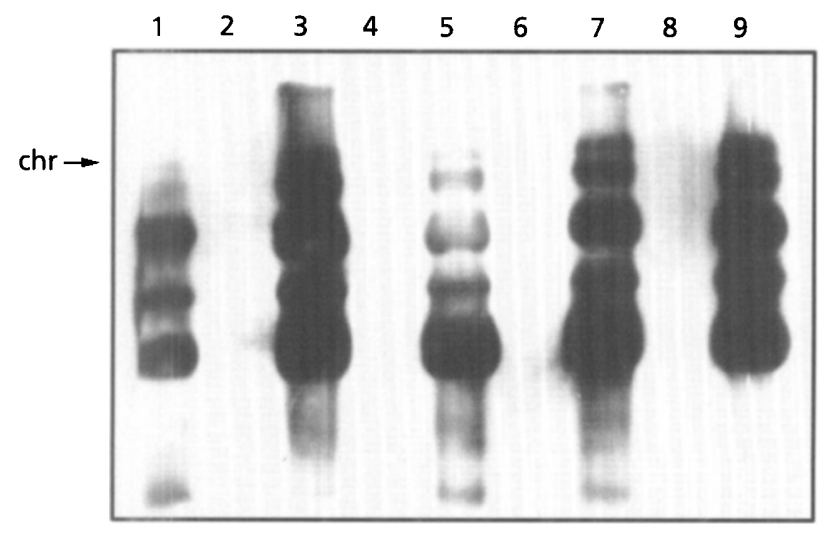

Fig. 3. Southern hybridization analysis of $V$. cholerae strains after infection with phage 493. Total DNA from different 01 and non-O1 strains was electrophoresed on a $1 \%$ agarose gel and then transferred onto nylon membrane (Hybond +; Amersham). After transfer, the membrane was hybridized with phage DNA labelled with digoxigenin. Lanes 1-9: 493, 4450, 4450/493 (after phage infection), 6707,6707/493, AP2, AP2/493, MAK757 and MAK757/493, respectively. Lanes 1-3, 6 and 7 are O139 strains; lanes 4, 5, 8 and 9 are El Tor. chr, Chromosomal DNA.

inhibition of growth, but not plaque formation, was rarely observed and then only with undiluted 493 (Table 1). Interestingly, the El Tor biotype strains which were refractory to lysis with phage 493 were isolated from Bangladesh in 1995-1996, when El Tor strains were again predominant (Faruque et al., 1996; International Centre for Diarrhoeal Disease Research, Bangladesh, 1996; Sharma et al., 1997), and one strain (out of five tested) isolated in 1994. Colonial opacity or translucency had no effect. Other vibrio species tested, including representative strains of $V$. fluvialis, $V$. harveyi, $V$. hollisae, V. parahaemolyticus and V. vulnificus and A. damsela, were resistant.

\section{Infection by choleraphage}

Phage 493 was temperate. Growing cells were picked from the centre of plaques and streaked for single colonies. Stereoscopic examination of these colonies using transmitted oblique illumination (Finkelstein et al., 1997) revealed that marked alteration in colonial morphology occurred as a result of infection with phage 493 (Fig. 2a, b). The colonies become hypervariable in both opacity and size. Other O139 and El Tor strains examined gave similar results. All the infected strains and colonial variants tested produced phage DNA. Plasmid DNA from these strains was compared before and after infection. In all the infected strains, hybridizing extrachromosomal elements were seen which were not present prior to exposure to 493 phage. Southern hybridization of total DNA from these strains with the virion DNA (Fig. 3) indicated the presence of sequences homologous to the phage DNA in both chromosomal and extrachromosomal loci.
Total and plasmid DNA preparations from hybridizing strains digested with several restriction enzymes were subjected to Southern blot analyses using virion DNA as a probe. These analyses revealed the presence of a single EcoRI site in the phage RF DNA (plasmid) as evidenced by a single hybridizing band of $9.3 \mathrm{~kb}$. However, in the total DNA preparations, this $9 \cdot 3 \mathrm{~kb}$ fragment was superimposed on a ladder of chromosomal restriction fragments (data not shown). The chromosomal hybridization pattern was suggestive of random phage insertions as has been demonstrated with phage VSK (Kar et al., 1996). All infected cells were able to produce phage particles. Comparison of total protein profiles by SDS-PAGE revealed an $18 \mathrm{kDa}$ protein in infected strains Peru 6707 and AJ27-404 (selected as examples of non-hybridizing strains; Table 2) (results not shown). Phage from O139 strain PO7 had somewhat different effects on colony morphology than 493 (Fig. 2c). Although colonies infected with $\mathrm{PO} 7$ phage were hypervariable with regard to opacity, unlike 493-infected strains, colony size was more uniform. It should be noted that the sensitivity of indicator strains to phage infection increased after additional broth passages and that only young cultures of the indicator strains were sensitive to phage in the overlay assay; overnight cultures were resistant (results not shown). This may be related to expression of the phage receptor.

\section{Distribution of 493-phage-related sequences}

The virion DNA hybridized with 21 out of 320139 strains examined (Table 2; Fig. 4). Southern hybridizations were performed repeatedly with both total and plasmid DNA preparations and the results are summarized in Table 2. Differences can be seen in hybridization patterns between O139 isolates from the same year and the same location (Fig. 4). Interestingly, DNA homology - both plasmid and chromosomal was observed with the capsulated O31 strain, NRT36S, isolated at Narita Airport, Japan, before 1990 (Johnson et al., 1992). No DNA homologous to the phage was found in any of the $16 \mathrm{O} 1$ serogroup El Tor or classical biotype strains isolated at different times or places, or strain MO1 (Table 2). No homology was observed in representative strains of other vibrio species (see above). pEAJ46 was also used as a probe to detect phage 493 sequences in these strains. Under low stringency conditions (Litwin et al., 1992), the spectrum of hybridization was the same as that seen with total phage 493 DNA as a probe; however, with high stringency, only cells infected with the phage gave positive signals. Therefore, although phage 493 DNA was found to be widely distributed among O139 (but not O1) vibrios, some variability existed in its sequence.

\section{Other phages}

Phage 493 is not the only phage we have observed in our collection. O139 strain PO7, isolated in India in 1993, produces both a filamentous phage, VSK, which has 
Table 2. Hybridization of $V$. cholerae total DNA with 493 phage DNA

\begin{tabular}{|c|c|c|c|c|}
\hline Serotype* & Source & Year & Strain & Hybridization $\dagger$ \\
\hline \multirow[t]{32}{*}{ O139 } & India & 1993 & AP1-1 & $\mathrm{p}, \mathrm{chr}$ \\
\hline & & & AP2-1 & - \\
\hline & & & MDO12 & - \\
\hline & & & MO45 & $\mathrm{p}, \mathrm{chr}$ \\
\hline & & & PO2 & $\mathrm{p}, \mathrm{chr}$ \\
\hline & & & PO7 & $\mathrm{p}, \mathrm{chr}$ \\
\hline & & & SG25-1 & $\mathrm{p}, \mathrm{chr}$ \\
\hline & & & VO20-1 & - \\
\hline & Bangladesh & & 1837 & $\mathrm{p}, \mathrm{chr}$ \\
\hline & & & 1838 & - \\
\hline & & & 1852 & - \\
\hline & & & 1855 & $\mathrm{p}, \mathrm{chr}$ \\
\hline & & & 4550 & - \\
\hline & & & 4460 & - \\
\hline & & 1994 & AJ27-370 & - \\
\hline & & & AJ27-404 & - \\
\hline & & & AJ27-425 & $\mathrm{p}, \mathrm{chr}$ \\
\hline & & & AJ27-493 & $\mathrm{p}, \mathrm{chr}$ \\
\hline & & & AJ27-495 & $\mathrm{p}, \mathrm{chr}$ \\
\hline & & & AJ27-513 & $\mathrm{p}, \mathrm{chr}$ \\
\hline & & & AJ27-514 & - \\
\hline & & 1995 & 1658 & $\mathrm{p}, \mathrm{chr}$ \\
\hline & & & 15049 & $\mathrm{p}, \mathrm{chr}$ \\
\hline & & & 150648 & $\mathrm{p}, \mathrm{chr}$ \\
\hline & & & 1433569 & $\mathrm{p}, \mathrm{chr}$ \\
\hline & & & 1433574 & $\mathrm{p}, \mathrm{chr}$ \\
\hline & & 1996 & 1936 & $\mathrm{p}, \mathrm{chr}$ \\
\hline & & & 19641 & $\mathrm{p}, \mathrm{chr}$ \\
\hline & & & 19936 & $\mathrm{p}, \mathrm{chr}$ \\
\hline & & & 20479 & $\mathrm{p}, \mathrm{chr}$ \\
\hline & & & 20583 & $\mathrm{p}, \mathrm{chr}$ \\
\hline & & & 21732 & - \\
\hline \multirow[t]{2}{*}{$\mathrm{O} 1, \mathrm{CI}$} & Calcutta, India & 1945 & $569 \mathrm{~B}$ & - \\
\hline & Bangladesh & 1985 & 21152 & - \\
\hline EI & Peru & 1991 & 6707 & - \\
\hline \multirow[t]{13}{*}{$\mathrm{EO}$} & Celebes & 1937 & MAK757 & - \\
\hline & Vietnam & 1964 & 3083 & - \\
\hline & Bangladesh & 1995 & 1718 & - \\
\hline & & & 150640 & - \\
\hline & & & 150659 & - \\
\hline & & & 150678 & - \\
\hline & & & 1433930 & - \\
\hline & & 1996 & 2073 & - \\
\hline & & & 19235 & - \\
\hline & & & 19992 & - \\
\hline & & & 20049 & - \\
\hline & & & 20259 & - \\
\hline & & & 20270 & - \\
\hline O31 & Japan & 1990 & NRT36S & $\mathrm{p}, \mathrm{chr}$ \\
\hline Atypical-O1 & India & 1993 & MO1 & - \\
\hline
\end{tabular}

*C, Classical; E, El Tor; I, Inaba serotype; O, Ogawa serotype.

tp, Plasmid; chr, chromosomal; -, no hybridization. 


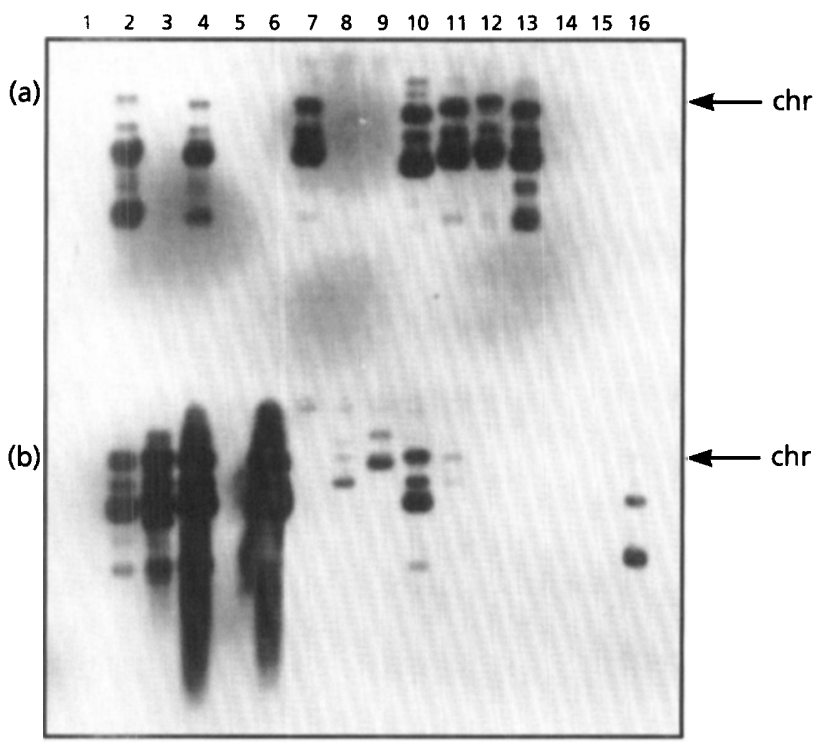

Fig. 4. Southern hybridization analysis of $V$. cholerae DNA. Total DNA from different $\mathrm{O} 1$ and non-O1 strains was electrophoresed on a $1 \%$ agarose gel and then transferred onto nylon membrane (Hybond +; Amersham). After transfer, the membrane was hybridized with phage DNA labelled with digoxigenin. (a) Lanes: 1, $1 \mathrm{~kb}$ loading standard; and 2-16, 0139 strains 1837, 1838, 1855, 1852, 4460, AP1, AP2, MDO12, MO45, PO2, PO7, SG25, VO20, 370 and 404, respectively. (b) Lanes: 1, 1 kb loading standard; and 2-16, 425, 495, 493, 439, $513,514,1433569,1658,150549,1433574,1718,150659$, 1433930, 150678 and NRT36S, respectively. Lanes 2-11 are 0139; $12-15$ are El Tor; and 16 is O31. chr, Fragmented chromosomal DNA.

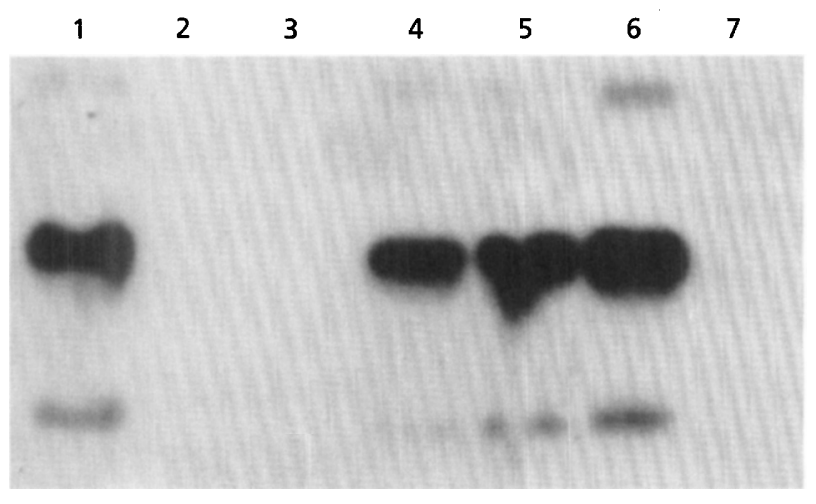

Fig. 5. Southern hybridization analysis of plasmid DNA of $V$. cholerae strains with plasmid pEAJ46 as a probe. Lanes 1-7: 493, 404, 6707, 404 infected with phage 493 (404/493), 6707/493, PO7/493 and PO7, respectively. All strains are 0139 except 6707 (lanes 3 and 5), which is El Tor.

been partially characterized, and a kappa-type phage (Kar et al., 1996). In the present study, strain PO7 DNA was shown to hybridize with total DNA from phage 493 (Table 2) but not with the specific probe pEAJ46 derived from phage 493 (Fig. 5).

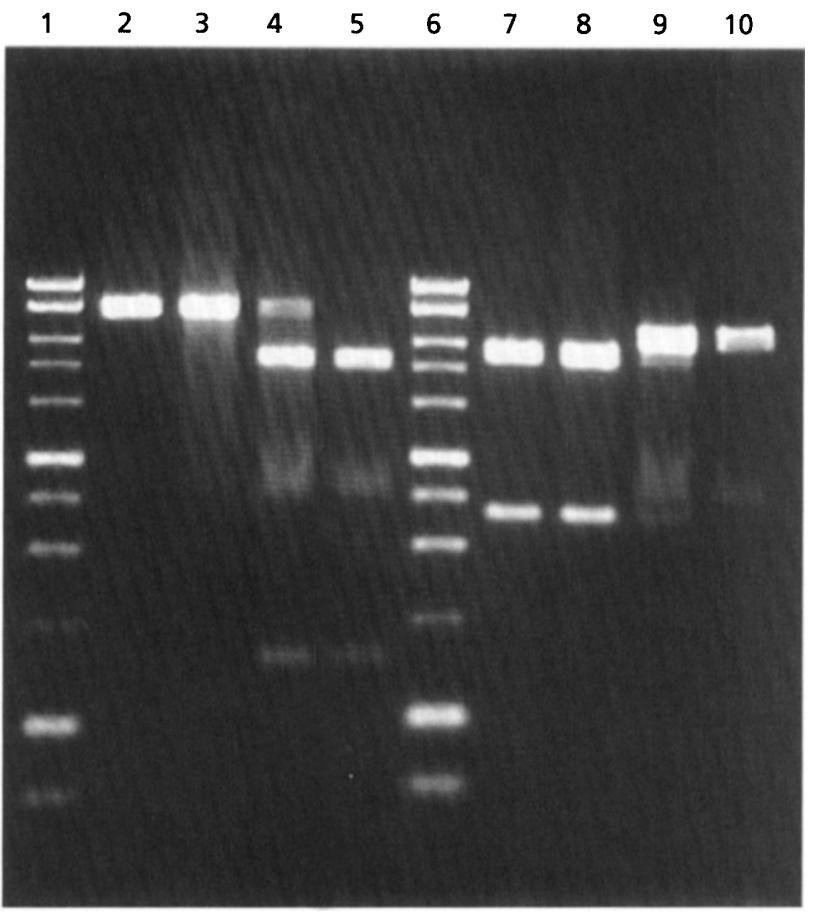

Fig. 6. Plasmid profiles of strains 493 and $P O 7$ before and after cross-infection. Lanes: 1 and $6,1 \mathrm{~kb}$ loading standard (Promega); 2-5, samples cut with EcoRI (lane 2, 493; lane 3, PO7/493; lane 4, 493/PO7; lane 5, PO7); and 7-10, the same samples cut with HindllI.

Interestingly, when strain $\mathrm{PO} 7$ was exposed to phage 493, the replicative form of phage PO7 appeared, visually, to be replaced by 493 (Fig. 6); however, Southern blot and hybridization analyses revealed that PO7 DNA was diminished but not completely absent. Conversely, when strain 493 was exposed to phage PO7, both phages appeared to replicate in the infected recipient (Fig. 6). These results were identical for each of ten representative colonies.

The encapsulated O31 strain NRT36S also produces a phage which, as stated above, has some homology to 493 but not to the pEAJ46 probe. Like 493, it acts upon its parent and does not have self-immunity.

\section{Search for 493 phage receptor}

Because TcpA was demonstrated to be the receptor for the filamentous $\operatorname{ctx} \phi$, we examined the possibility that TcpA could also be the receptor for 493. TcpA is known to be under control of ToxR (Waldor \& Mekalanos, 1994). Three independent ToxR ${ }^{-}$mutants were obtained by integration of plasmid pVM55; the phenotypes of these mutants were confirmed by SDS-PAGE analysis as previously described by Waldor \& Mekalanos (1994). These mutants, in addition to the $\Delta t c p A$ mutant KHT52, were equally as sensitive to 493 as their wild-type parents, thus indicating that TcpA is not involved. 


\section{DISCUSSION}

The vibrios which cause epidemic cholera have a highly developed ability to present new and challenging problems to those who would study them. They are also a highly conserved group. More than 150 serotypes of $V$. cholerae have now been identified but, until 1961, as far as we know, all epidemic cholera was caused by only two serotypes, Inaba and Ogawa, of O group 1 of the classical biotype first described by Robert Koch in 1883 (Anonymous, 1883). In 1961, the El Tor biotype (first recognized in 1905) emerged, presumably from Indonesia (de Moor, 1939), to cause what is regarded as the seventh great cholera pandemic. It is noteworthy that cholera patients in India before 1964 had classical O1 whereas, by $1965,89 \%$ of 2000 strains tested were phage-typed as El Tor (Mukerjee, 1974). How did the 'new' El Tor biotype displace the classical biotype from its home in India? Similarly, in 1992, the O139 serotype emerged in India and Bangladesh and soon outnumbered, for a while, the resident El Tor biotype which, aside from the loss of the $\mathrm{O} 1$ antigen and the gain of a capsule, it closely resembled. How did O139 arise (from El Tor?) and how did it gain - and then lose ascendancy? We are interested in the possibilities that choleraphage(s) could have played significant roles in the horizontal transmission of genetic information and in the manifestations of 'bacteriological warfare' which ensued.

Large numbers of choleraphages, mostly lytic ones, have previously been identified and been useful in distinguishing biotypes and in typing $V$. cholerae strains (Guidolin \& Manning, 1987). Others, including recent isolates from O139 strains, have been associated with: (a) virulence (Parker et al., 1970; Takeya \& Shimodori, 1963); (b) induction of toxinogenesis (Siddiqui \& Bhattacharyya, 1987); and (c) biotype transition (Mitra, 1989). Most recently, Waldor \& Mekalanos (1996) have shown that the 'virulence cassette' of choleragenic vibrios is carried by a chromosomally integrated filamentous phage using TcpA as a receptor. Hacker et al. (1997) have recently summarized the potential role of bacteriophage in horizontal gene transfers involved in 'pathogenicity islands' of other pathogenic bacteria.

In the present work, we have found that O139 strains produce bacteriophage which could be involved in horizontal genetic exchange and could provide some selective advantage. One phage (493) was selected for extensive study. Phage 493 is a lysogenic filamentous phage which produces turbid plaques and has characteristics which are similar to those of other filamentous phages (Rasched \& Oberer, 1986). It is moderately thermostable and resistant to a broad range of $\mathrm{pH}$, but it is sensitive to chloroform and proteolytic agents. Like other filamentous phages, it has single-stranded closed circular DNA but some molecules have an $\sim 2.3 \mathrm{~kb}$ stem-loop structure (Fig. 1b) which could represent a transposable element. This structure was not observed in the recently described filamentous phage VSK from $V$. cholerae O139 (Kar et al., 1996). Two fibres reminiscent of attachment fibres of non-filamentous phages (Fraenkel-Conrat, 1985) were visualized at one end of some particles (not shown).

The infection and propagation of phage 493 within host cells is not affected by $t c p A$ deletion or tox $R$ mutations. Therefore, ToxR-regulated components can be excluded as being necessary for active infection (attachment, entry, replication, assembly, etc.), although we can not rule out the possibility that some of these components were constitutively expressed at low levels in the Tox $\mathrm{R}^{-}$insertional mutant. The importance of TcpA as the phage receptor can categorically be eliminated, thus clearly distinguishing this phage from the previously described filamentous $\operatorname{ctx} \phi$ phage (Waldor \& Mekalanos, 1996). Preliminary data suggest that another type IV pilus, the mannose-sensitive haemagglutinin, may be the receptor for phage 493 (work in progress).

The phage had an interesting spectrum of activity (Table 1). All but one of the 33 strains of O139 were highly sensitive. Thirty-one of the 46 strains of O1 biotype El Tor tested were sensitive. The observation that only the recent El Tor isolates were resistant raises the possibility that choleraphage such as 493 could have played a significant role in the emergence and the subsequent decline of $\mathrm{O} 139$ in India and Bangladesh. The potential role of choleraphage in the evolution of epidemic $V$. cholerae strains was summarized recently by Mooi \& Bik (1997). It should be recognized that the dramatic population changes - El Tor over classical biotype since 1961 and O139 over El Tor in 1992 (and back) - must be dependent on the ability of the invading strain to exert a superior survival advantage over the resident strain in the environment. Recognizing that a single infected bacterium could generate hundreds of phage particles, phage could play the role by reducing the quantum of infection of a phage-sensitive resident strain in the environment while the invading strain propagates. The emergence of the phage-resistant El Tor biotype in Calcutta was recently demonstrated to coincide with the appearance of a hitherto unknown ribotype of $\mathrm{O} 1 \mathrm{El}$ Tor (Sharma et al., 1997).

The ability to infect and co-exist in the same cell was demonstrated with phages 493 and PO7. It is obvious that PO7 is related to 493 because of cross-hybridizing sequences contained within their genomes (Fig. 4). However, the two phages have some differences as evidenced by the observations that PO7 DNA did not hybridize to pEAJ46 derived from 493 and the PO7- and 493-associated plasmids have distinctive migration patterns on agarose gels (Fig. 6). These observations, taken together, raise the intriguing prospect of constant genetic exchange between 493-related phages, thus generating 'new' phages with slightly different properties. These new phages may then serve as important vehicles in the maintenance of genetic diversity and exchange among $V$. cholerae strains.

Our observations indicate that 493 may participate in horizontal transmission of genetic information (at least 
under laboratory conditions). Homologous DNA was detected, both chromosomally and extrachromosomally, in infected strains. Infection is also accompanied by expression of an $\sim 18 \mathrm{kDa}$ protein in both El Tor and $\mathrm{O} 139$ strains which were previously non-hybridizing, and by marked alteration in colonial morphology of infected strains (Fig. 2). Homologous DNA is widely, but not universally, distributed among $\mathrm{O} 139$ but not $\mathrm{O} 1$ strains (Table 2; Fig. 4). It is not yet clear, from our observations, why O139 strains are heterogeneous in their content of 493 homologous DNA sequences or whether 493 could have been involved in the evolution of O139. It is not unlikely that a 493-like phage was involved. We should take note that 493 DNA also hybridized with a non-O1 (O31) strain (NRT36S) which was isolated before O139 was recognized. NRT36S also produces a phage which can infect El Tor strains with low efficiency (results not shown).

The fact that 493-related sequences existed in non-O1 vibrios prior to the emergence of $\mathrm{O} 139$ suggests the possibility of a cause/effect relationship. However, NRT36S does not react with anti-O139 antiserum (Sengupta et al., 1996) (results not shown) so it is not a progenitor strain for either $\mathrm{O} 139$ somatic antigen or capsule. Other strains and species which are serologically cross-reactive (Isshiki et al., 1996; Knirel et al., 1996) have not yet been examined for DNA homologies, but filamentous phages such as 493 could provide a mechanism for horizontal transmission of the essential genetic information. While it is unusual that O139 emerged with epidemic capability, such genetic exchange may be more common than previously recognized.

\section{ACKNOWLEDGEMENTS}

This work was supported by US Health Service grant AI17312 to R.A.F. from the National Institute of Allergy and Infectious Diseases. We appreciate the technical assistance of Don Carpenter and, also, the generosity of M. J. Albert, J. Johnson, J. Mekalanos, G. B. Nair, Y. Takeda, R. Taylor and $\mathrm{K}$. Wachsmuth for providing strains and mutants. Discussion with J. Mekalanos was also helpful.

\section{REFERENCES}

Albert, M. J. (1994). Vibrio cholerae O139 Bengal. J Clin Microbiol 32, 2345-2349.

Anonymous (1883). Dr. Koch's newly described cholera-organism. Br Med J 1883, 828-829.

Bik, E. M., Bunschoten, A. E., Gouw, R. D. \& Mooi, F. R. (1995). Genesis of the novel epidemic Vibrio cholerae O139 strain: evidence for horizontal transfer of genes involved in polysaccharide synthesis. EMBO J 14, 209-216.

Faruque, A. S. G., Fuchs, G. J. \& Albert, M. J. (1996). Changing epidemiology of cholera due to Vibrio cholerae O1 and O139 Bengal in Dhaka, Bangladesh. Epidemiol Infect 116, 275-278.

Finkelstein, R. A., Boesman-Finkelstein, M., Sengupta, D. K., Page, W. J. \& Phillips, T. E. (1997). Colonial opacity variations among the choleragenic vibrios. Microbiology 143, 23-34.

Fraenkel-Conrat, H. (1985). The Viruses: Catalogue, Characterization, and Classification. New York: Plenum.
Garon, C. F. (1982). Electron microscopy of nucleic acids. In Gene Amplification and Analysis, vol. 2, pp. 573-585. Edited by J. G. Chirikjian \& T. S. Papas. New York: Elsevier.

Garon, C. F. (1986). Electron microscopy of nucleic acids. In Ultrastructure Techniques for Microorganisms, pp. 161-181. Edited by H. C. Aldrich \& W. J. Todd. New York: Plenum.

Gay, F. P. (1935). The vibrios and Asiatic cholera. In Agents of Disease and Host Resistance, pp. 597-598. Springfield, IL \& Baltimore, MD: C. C. Thomas.

Guidolin, A. \& Manning, P. A. (1987). Genetics of Vibrio cholerae and its bacteriophages. Microbiol Rev 51, 285-298.

Hacker, J., Blum-Oehler, G., Mühldorfer, I. \& Tschäpe, H. (1997). MicroReview: pathogenicity islands of virulent bacteria: structure, function and impact on microbial evolution. Mol Microbiol 23, 1089-1097.

International Centre for Diarrhoeal Disease Research, Bangladesh (1996). Research highlights of 1995. Glimpse 18, 3.

Isshiki, Y., Kondo, S., Iguchi, T., Sano, Y., Shimoda, T. \& Hisatsune, K. (1996). An immunochemical study of serological cross-reaction between lipopolysaccharides from Vibrio cholerae O22 and O139. Microbiology 142, 1499-1504.

Johnson, J. A., Panigrahi, P. \& Morris, J. G., Jr (1992). Non-O1 Vibrio cholerae NRT36S produces a polysaccharide capsule that determines colony morphology, serum resistance, and virulence in mice. Infect Immun 60, 864-869.

Kaper, J. B., Morris, J. G., Jr \& Levine, M. M. (1995). Cholera. Clin Microbiol Rev 8, 48-86.

Kar, S., Ghosh, R. K., Ghosh, A. N. \& Ghosh, A. (1996). Integration of the DNA of a novel filamentous bacteriophage VSK from Vibrio cholerae $\mathrm{O} 139$ into the host chromosomal DNA. FEMS Microbiol Lett 145, 17-22.

Knirel, Y. A., Senchenkova, S. N., Jansson, P.-E., Weintraub, A., Ansaruzzaman, M. \& Albert, M. J. (1996). Structure of the Ospecific polysaccharide of an Aeromonas trota strain crossreactive with Vibrio cholerae O139 Bengal. Eur J Biochem 238, 160-165.

Laemmli, U. K. (1970). Cleavage of structural proteins during the assembly of the head of bacteriophage T4. Nature 227, 680-685.

Litwin, C. M., Boyko, S. A. \& Calderwood, S. B. (1992). Cloning, sequencing, and transcriptional regulation of the Vibrio cholerae fur gene. J Bacteriol 174, 1897-1903.

Miller, V. L. \& Mekalanos, J. J. (1988). A novel suicide vector and its use in construction of insertion mutations: osmoregulation of outer membrane proteins and virulence determinants in Vibrio cholerae requires toxR. J Bacteriol 170, 2575-2583.

Mitra, S. N. (1989). Mutation induced by vibriophage PS166 infection changes biotype and phage type of Vibrio cholerae. J Med Microbiol 30, 137-141.

Mooi, F. R. \& Bik, E. M. (1997). The evolution of epidemic Vibrio cholerae strains. Trends Microbiol 5, 161-165.

de Moor, C. E. (1939). Epidemic cholera in South Celebes caused by vibrio El Tor. Meded Drenst Volksgezondheid Ned-Indië 28, 320-355.

Mukerjee, S. (1974). Vibrio phages and phage-typing of cholera vibrios. In Cholera, pp. 61-74. Edited by D. Barua \& W. Burrows. Philadelphia, PA: W. B. Saunders.

Pajni, S., Chowdhury, N. R., Ghosh, A., Kar, S. \& Ghosh, R. K. (1995a). Characterization of phage O139, a Vibrio cholerae O139 temperate bacteriophage with cohesive DNA termini. FEMS Microbiol Lett 131, 69-74.

Pajni, S., Sharma, C., Bhasin, N., Ghosh, A., Ramamurthy, T., Nair, 
G. B., Ramajayami, S., Das, B., Kar, S., Roychowdury, S. \& Ghosh, R. K. (1995b). Studies on the genesis of Vibrio cholerae O139: identification of probable progenitor strains. J Med Microbiol 42, 20-25.

Parker, C., Richardson, S. H. \& Romig, W. R. (1970). Production of bacteriophage-associated materials by Vibrio cholerae: possible correlation with pathogenicity. Infect Immun 1, 417-420.

Rasched, I. \& Oberer, E. (1986). Ff coliphages: structural and functional relationships. Microbiol Rev 50, 401-427.

Reidl, J. \& Mekalanos, J. J. (1995). Characterization of Vibrio cholerae bacteriophage $\mathrm{K} 139$ and use of a novel mini-transposon to identify a phage-encoded virulence factor. Mol Microbiol 18, 685-701.

Rowe, B. \& Frost, J. A. (1992). Vibrio phages and phage-typing. In Cholera, pp. 95-105. Edited by D. Barua \& W. B. Greenough. New York: Plenum.

Sambrook, J., Fritsch, E. F. \& Maniatis, T. (1989). Molecular Cloning: a Laboratory Manual, 2nd edn. Cold Spring Harbor, NY: Cold Spring Harbor Laboratory.

Sengupta, D. K., Boesman-Finkelstein, M. \& Finkelstein, R. A. (1996). Antibody against the capsule of Vibrio cholerae O139 protects against experimental challenge. Infect Immun 64, 343-345.

Sharma, C., Nair, G. B., Mukhopadhyay, A. K., Bhattacharya, S. K., Ghosh, R. K. \& Ghosh, A. (1997). Molecular characterization of Vibrio cholerae O1 biotype El Tor strains isolated between 1992 and 1995 in Calcutta, India : evidence for the emergence of a new clone of the El Tor biotype. J Infect Dis 175, 1134-1141.

Siddiqui, A. I. \& Bhattacharyya, F. K. (1987). Phage-induced change of toxigenesis in Vibrio cholerae. J Med Microbiol 23, 331-334.

Stroeher, U. H., Jedani, K. E., Dredge, B. K., Morona, R., Brown, M. H., Karageorgos, L. E., Albert, M. J. \& Manning, P. A. (1995). Genetic rearrangements in the rfb regions of Vibrio cholerae $\mathrm{O} 1$ and O139. Proc Natl Acad Sci USA 92, 10374-10378.

Takeya, K. \& Shimodori, S. (1963). 'Prophage-typing' of El Tor vibrios. J Bacteriol 65, 957-958.

Thelin, K. H. \& Taylor, R. K. (1996). Toxin-coregulated pilus, but not mannose-sensitive hemagglutinin is required for colonization by Vibrio cholerae $\mathrm{O} 1 \mathrm{El}$ Tor biotype and $\mathrm{O} 139$ strains. Infect Immun 64, 2853-2856.

Waldor, M. K. \& Mekalanos, J. J. (1994). ToxR regulates virulence gene expression in non-O1 strains of Vibrio cholerae that cause epidemic cholera. Infect Immun 62, 72-78.

Waldor, M. K. \& Mekalanos, J. J. (1996). Lysogenic conversion by filamentous phage encoding cholera toxin. Science 272, 1910-1914.

Received 22 May 1997; revised 10 September 1997; accepted 26 September 1997. 